\title{
The Relationship between Trauma, PTSD, and Mental Health Problems among Palestinian Refugee Children
}

\author{
Abdelaziz M Thabet ${ }^{1 *}$ and Sanaa $\mathrm{S}$ Thabet ${ }^{2}$ \\ ${ }^{1}$ Emeritus Professor of Psychiatry, Al Quds University, Consultant at Child and Family Training and Counselling Center-NGO, Palestine, Affiliated
} Professor with Center for Refugee Studies, York University, Canada

${ }^{2}$ Director of Child and Family Training and Counselling Center, NGO, Palestine

Submission: May 21, 2018; Published: June 18, 2018

*Corresponding author: Abdelaziz M Thabet, Emeritus Professor of Psychiatry, Al Quds University, Consultant at Child and Family Training and Counselling Center-NGO, Palestine-Affiliated Professor with Center for Refugee Studies, York University, Canada Email: abdelazizt@hotmail.com

Abstract

Aim: The aim of the study was to explore the relationship between trauma on Palestinian refugee children PTSD and Mental Health problems.

Method: The study population included 76 children, 42 boys which represented $55.3 \%$ and 34 girls which represented $44.7 \%$. Age ranged from 7 to 15 years with mean age 10.55 living in refugee camp in middle area of the Gaza Strip. Children were interviewed with Socio demographic status scale, Children's revised impact of event scale (CRIES-13), and Strengths and Difficulties Questionnaire (SDQ) (Goodman, 1997).

Results: The most common reported post traumatic stress reactions were: try to remove it from his memory (46.1\%), have sleep problems (43.4\%), Alert and watchful even when there is no obvious need to be (40\%). Children's mean Children's revised impact of event scale (CRIES-13) items was 39.05 , intrusion was 12.05 , avoidance was 15.09, and hyperarousal was 11.86. According to cut off point of 33 and more as PTSD, $67.1 \%$ had post traumatic stress reactions. The results showed no sex differences in total PTSD and subscales. The study showed that the most commonly reported behavioral and emotional problems in children by parents were: considerate of other people's feelings (59.5\%), shares readily with other children (54.1\%), and restless, overactive, cannot stay still for long (49.3\%). The study showed that parents reported from 5-29 symptoms with mean 17.59 , conduct disorder mean was 3.9 , mean hyperactivity was $5(\mathrm{SD}=2.10)$, mean emotional problems was 4.88 , mean peers problems was 3.87 , and mean prosocial problems was 7.17. Using SDQ for parents, $53.7 \%$ of children were rated as being caseness, $60.3 \%$ had emotional problems, $60.3 \%$ had conduct problems, $22.2 \%$ of them were hyperactive, $49.3 \%$ had peer problems, and $21 \%$ had prosocial behaviour. Result showed that there was significant correlation between total PTSD and total SDQ, hyperactivity, emotional problems, and prosocial behaviour.

Clinical Implications: Our findings have public health and clinical implications because they highlight the importance of child mental health including PTSD as a significant factor affecting children's psychosocial development. There is a need for immediate psychosocial interventions targeting children mental health, to help children with mental health problems. We need to educate and support parents, teachers and other caregivers so they can support the emotional well-being of children exposed to political violence Such interventions may consist of group discussion meetings for mothers to support them and increase their sense of well-being, self-confidence and ability to care for their children in this difficult situation.

Keywords: Children; Refugee; PTSD; SDQ; Gaza Strip

Abbreviations: LSD: Least Significant Difference; SDQ: Strengths and Difficulties Questionnaire; PTSD: Partial Post Traumatic Stress Disorder; CRIES: Children's Revised Impact of Event Scale; SPSS: Statistical Package for the Social Science

\section{Introduction}

Reviews of the international literature showed that degree of war exposure predicted PTSD among children. PTSD symptoms in children during periods of active war have been studied only in a handful of locations, including Palestine lbedour et al. [1]; Qouta et al. [2]; Thabet et al. [3]. Similarly after the 2014 war on Gaza, as El khodary and Samara [4] in study the effect of exposure to war-traumatic events, stressful life events, and other variables on mental health of Palestinian children and adolescents in the 2012 Gaza War, participants were chosen from the Gaza Strip using a stratified random sampling method. The sample consisted of 1029 students aged 11-17 years. The study showed that $88 \%$ of students had experienced personal trauma, $84 \%$ had witnessed trauma to others, and $88 \%$ had seen demolition of property during the war. Boys reported more exposure to personal trauma, witnessing trauma to others, seeing demolition of property, and overall traumatic events compared to girls. Girls reported more exposure to stressful life events, exposure to trauma (not related to war-trauma), PTSD, and depression. The showed that $54 \%$ of 
students had a diagnosis of PTSD diagnosis. They found a positive correlation between the age and exposure to war-traumatic events and stressful life events and between family size and exposure to war-traumatic events and PTSD. Thabet et al. (2016a) in study the relationship between trauma due to winter storm Alexa, post-traumatic stress disorder and other mental health problems of Palestinian children in Gaza Strip, found that mean post-traumatic stress disorder symptoms was 28.82, intrusion symptoms was 7.4 , avoidance symptoms was 10.08 , and arousal symptoms was $11.33,47.6 \%$ of children were considered as post traumatic stress disorder. Girls reported significantly more post traumatic stress disorder symptoms and avoidance symptoms compared to boys. Recently, Dawas \& Thabet [5] in study a sample consisted of 400 secondary school students, the results showed that $24 \%$ adolescents had partial post traumatic stress disorder (PTSD), and $10.5 \%$ had full criteria of. Thabet \& Vostanis [6] in a study include 200 parents and 200 children age 9-18 years in the middle area of the Gaza Strip, for children, mean traumatic events were 7.88, prevalence of PTSD in children was 70.1\%; anxiety disorder $(33.9 \%)$, general mental health problems rated by parents (42.7); conduct disorder (36.8\%); hyperactivity (22.8\%), emotional problems (24.4\%), peers problems (60.1\%), and prosocial problems (20.2\%). Al Sheikh \& Thabet [7] in study a sample consisted of 400 students (200 boys and 200 girls). The study showed that mean traumatic experiences reported was 12.19. Boys had been exposed more than girls. The study showed that $25 \%$ of adolescents reported partial PTSD and $9.3 \%$ had full criteria of PTSD. Boys reported more PTSD than girls. Recently, Lee et al. [8] in a study a sample of 57 students ( 29 boys and 28 girls) who survived the Sewol ferry disaster. The results showed that $26.3 \%$ of participants were classified in the clinical group by the Child Report of Post-traumatic Symptoms score. Based on a generalized linear model, Poisson distribution, and log link analyses, PTSD symptoms were positively correlated with the number of exposed traumatic events, peers and social support, peri-traumatic dissociation and post-traumatic negative beliefs, and emotional difficulties. The aim of the study was to explore the relationship between trauma on Palestinian refugee children PTSD and Mental Health problems.

\section{Method}

\section{Setting and Participants}

Bureij camp is a comparatively small refugee camp located in the middle of the Gaza Strip. The camp is near Maghazi and Nuseirat refugee camps. Bureij camp was built in the 1950s to house approximately 13,000 refugees who until then had lived in British army barracks and tents. The refugees who settled in Bureij had mostly come from towns east of Gaza, such as Falouja. Today, the refugee population of Bureij is more than 34,000. The study population included 76 children, 42 boys which represented $55.3 \%$ and 34 girls which represented $44.7 \%$. Age ranged from 7 to 15 years with mean age 10.55 living in refugee camp in middle area of the Gaza Strip.

\section{Instruments}

Sociodemographic status which gathered from children by questionnaire includes sex, age, place of residence, type of housing, number of sibling and rooms, father education and mother education etc. Children's revised impact of event scale (CRIES-13) Smith et al. [9]. All participants completed the CRIES-13, which include all of the items on CRIES-8 taken from the original Impact of Events Scale (18), as well as 5 items derived from the arousal criterion in the DSM-IV(2). Individual items are rated according to the frequency of their occurrence during the past week (None $=0$, rarely $=1$, Sometimes $=3$, and A lot $=5$ ) and in relation to a specific traumatic events written at the top of the scale. In this study we used the revised IES which was translated from English to Arabic and back Translated and no differences in both translations was found (8). The intrusion items include $1,4,8,9$, avoidance items include $2,6,7,10$, and hyperarousal items include $3,5,11,12,13$. The psychometric properties of CRIES (13item) IES were evaluated in a large population of children exposed to warfare in Croatia, Bosnia and Herzegovina (Smith et al., 2003). PTSD estimated a cutoff score of 30 and above as presence of PTSD. In this study the internal consistency of the scale, calculated using Cronbach's alpha was also high ( $\alpha=.75$ ); the split half reliability of the scale was .77.

\section{Strengths and Difficulties Questionnaire (SDQ) Goodman [10]}

The SDQ for parents or teachers of children $4 \pm 16$ years is a standardised questionnaire, which includes 25 items, which are the same for each age group for the different informants (13). Out of the 25 items, 14 describe perceived difficulties, 10 perceived strengths and one is neutral (gets on better with adults than with other children'). Each perceived difficulty item is scored on a $0 \pm 2$ scale (not true, somewhat true, and certainly true). Each perceived strength item is reversely scored, i.e. 2: not true, 1 : somewhat true, 0: certainly true. The 25 SDQ items are divided in the scales of Hyperactivity, Emotional Symptoms, Conduct Problems, Peer Problems and Prosocial Scale. A score is estimated for each scale and a total difficulty score for the four scales (excluding prosocial behavior, which was considered different from psychological difficulties). The scale was used in Palestinian society and showed high reliability Thabet and Vostanis [11]. In this study the reliability of the scales using Alpha Chronbach was 0.78 Split half is 0.79

\section{Study Procedure}

Given the vulnerable status of refugees, informed consent procedures emphasized that participation was voluntary and trained staff read aloud from a study information and consent script to child participants to ensure comprehension and provide the opportunity for questions. As part of the consent process, staff explained to both parents and children that their responses were confidential. The data collection was carried out by thee trained professionals with the supervision of the author. The data collection was done from 6th to 14th April 2008 after the 
incursion of the refugee camp by Israeli Military forces in Feb 2008 in the middle area in the Gaza Strip.

\section{Statistical Analysis}

Data entry and analysis will use a Statistical Package for the Social Science (SPSS, Version 23). Frequency and percent were used to express quantitative data of post-traumatic stress disorder, emotional and behavioural problems of children. For continuous variables means and standard deviation were reported. For differences between means of two group's parametric test were used such as t-test to compare sex of children and parents in mean of PTSD, total SDQ and subscales. While, ANOVA tests were used for measuring differences between more than two groups of continuous variables such PTSD, SDQ and place of residence. The researcher used least significant difference (LSD) test after one way ANOVA test, to explore further and compare the mean of one group with the mean of another. Pearson's correlation coefficient was used to test the association between PTSD and SDQ scores. The 0.05 alpha levels was accepted as a sign for statistical significance for all the statistical procedures.

Results

Sociodemographic Data: The sample consisted of 76 children, 42 boys which represented $55.3 \%$ and 34 girls which represented $44.7 \%$. Age ranged from 7 to 15 years with mean age $10.55(\mathrm{SD}=2.33)$ years. Palestinian families consisted of large number of children, as $2(9.2 \%)$ had 4 or less children, 30 families (56.6\%) had 5-7 children, and 18 families (34.2\%) had 8 or more children. Seventy five of children (98.7\%) live in the camp and 1 child (1.3\%) live in village. According to type of residence, 1 of children (1.3\%) live in a room with family, 14 of children (18.4\%) live in camp house 61 of children (80.3\%) live in own home (Table 1).

Table 1: Sociodemographic characteristic of the study sample $(\mathrm{N}=76)$.

\begin{tabular}{|c|c|c|}
\hline Items & No & \% \\
\hline \multicolumn{3}{|c|}{ 1- Sex } \\
\hline Male & 42 & 55.3 \\
\hline Female & 34 & 44.7 \\
\hline 2- Age & \multicolumn{2}{|c|}{ Mean = 10.41} \\
5-15 years $(2.573)$ \\
\hline \multicolumn{3}{|c|}{ 5 - No of siblings } \\
\hline 4 and less & 2 & 9.2 \\
\hline 5-7 siblings & 30 & 56.6 \\
\hline 8 and more siblings & 18 & 34.2 \\
\hline
\end{tabular}

Type of Post Traumatic Stress Reactions: As shown in Table 2, among Palestinian children, the most common reported post traumatic stress reactions were: try to remove it from his memory (46.1\%), have sleep problems (43.4\%), alert and watchful even when there is no obvious need to be $(40 \%)$ (Table 2).

Table 2: Percentages of Post-traumatic stress symptoms according to IES-children.

\begin{tabular}{|c|c|c|c|c|}
\hline & Not at all & Rarely & Some times & Often \\
\hline Think about it even when he don't mean to & 5.3 & 21.1 & 21.1 & 36.8 \\
\hline Try to remove it from his memory & 6.6 & 21.1 & 21.1 & 46.1 \\
\hline Have difficulties paying attention or concentrating & 9.2 & 17.1 & 17.1 & 32.9 \\
\hline Have waves of strong feelings about it & 3.9 & 23.7 & 23.7 & 35.5 \\
\hline Startle more easily or feel more nervous than he did before it happened & 3.9 & 23.7 & 23.7 & 27.6 \\
\hline Stay away from reminders of it (e.g. places or situations) & 10.7 & 18.7 & 18.7 & 32 \\
\hline Try not talk about it & 9.3 & 28 & 28 & 29.3 \\
\hline Pictures about it pop into his mind & 6.6 & 27.6 & 27.6 & 31.6 \\
\hline Things keep making him think about it & 10.5 & 19.7 & 19.7 & 30.3 \\
\hline Try not to think about it & 10.7 & 17.3 & 17.3 & 30.7 \\
\hline Get easily irritable & 13.2 & 13.2 & 13.2 & 28.9 \\
\hline Alert and watchful even when there is no obvious need to be & 8 & 20 & 20 & 40 \\
\hline Have sleep problems & 17.1 & 11.8 & 11.8 & 43.4 \\
\hline
\end{tabular}

Means and Standard Deviations of Post Traumatic Stress Reactions: Children's post traumatic stress reactions scores ranged between 7 and 63. Mean IES-13 items was 39.05 (SD= 7.15). Intrusion subscale mean was $12.05(\mathrm{SD}=4.3)$, avoidance subscale mean was 15.09 ( $\mathrm{SD}=5.83$ ), and hyperarousal subscale mean was $11.86(\mathrm{SD}=4.73)$. According to cut off point of 33 and more as PTSD, $32.9 \%$ of children had no post traumatic stress reactions and $67.1 \%$ had post traumatic stress reactions (Table 3 ).
Table 3: Means and standard deviation of IES-13 items and subscales.

\begin{tabular}{|c|c|c|}
\hline IES & Mean & SD \\
\hline Total IES-13 items & 39.05 & 12.61 \\
\hline Intrusion & 12.05 & 4.3 \\
\hline Avoidance & 15.09 & 5.83 \\
\hline Hyperarousal & 11.86 & 4.73 \\
\hline
\end{tabular}


Differences in PTSD and Sociodemographic Variables: In order to find differences in PTSD and means according to sociodemographic variables, independent $t$ test for two groups and One Way ANOVA for more than three groups. The results showed no sex differences in total PTSD and subscales. Post hoc test using Tukey's test showed that no age differences between the children age groups (7-11, 12-15, 16-18 years) and no differences according to number of siblings in the family.

Table 4: Frequency of psychological problems according to parents.

\begin{tabular}{|c|c|c|c|}
\hline & Yes & Sometimes & No \\
\hline 1. Considerate of other people's feelings & 59.5 & 33.8 & 6.8 \\
\hline 2. Restless, overactive, cannot stay still for long & 49.3 & 32 & 18.7 \\
\hline 3. Often complains of headaches, stomach-aches or sickness & 27 & 25.7 & 47.3 \\
\hline 4. Shares readily with other children (treats, toys, pencils etc.) & 54.1 & 32.4 & 13.5 \\
\hline 5. Often has temper tantrums or hot tempers & 37.3 & 33.3 & 29.3 \\
\hline 6. Rather solitary, tends to play alone & 20 & 41.3 & 38.7 \\
\hline 7. Generally obedient, usually does what adults request & 16 & 52 & 32 \\
\hline 8. Many worries, often seems worried & 33.3 & 40 & 26.7 \\
\hline 9. Helpful if someone is hurt, upset or feeling ill & 40.5 & 45.9 & 13.5 \\
\hline 10. Constantly fidgeting or squirming & 30.7 & 34.7 & 34.7 \\
\hline 11. Has at least one good friend & 30.1 & 23.3 & 46.6 \\
\hline 12. Often fights with other children or bullies them & 36.5 & 32.4 & 31.1 \\
\hline 13. Often unhappy, down-hearted or tearful & 16 & 52 & 32 \\
\hline 14. Generally liked by other children & 9.5 & 29.7 & 60.8 \\
\hline 15. Easily distracted, concentration wander & 35.1 & 45.9 & 18.9 \\
\hline 16. Nervous or clingy in new situation, easily losses confidence & 30.7 & 38.7 & 30.7 \\
\hline 17. Kind to younger children & 52.7 & 41.9 & 5.4 \\
\hline 18. Often argumentative with adults & 9.5 & 25.7 & 64.9 \\
\hline 19. Picked on or bullied by other children & 15.1 & 27.4 & 57.5 \\
\hline 20. Often volunteers to help others (parents, teachers, other children) & 52.1 & 37 & 11 \\
\hline 21. Can stop and thinks things over before acting & 18.9 & 48.6 & 32.4 \\
\hline 22. Can be spiteful to others & 13.5 & 21.6 & 64.9 \\
\hline 23. Gets on better with adults than with other children & 33.8 & 47.3 & 18.9 \\
\hline 24. Many fears, easily scared & 35.1 & 44.6 & 20.3 \\
\hline 25. Sees tasks through to the end, good attention span & 17.8 & 39.7 & 42.5 \\
\hline
\end{tabular}

General Mental Health Problems Using SDQ by Parents: The study showed that the most commonly reported behavioural and emotional problems in children by parents were: considerate of other people's feelings (59.5\%), shares readily with other children $(54.1 \%)$, and restless, overactive, cannot stay still for long (49.3\%) (Table 4).

Means and Standard Deviations of SDQ and Subscales: The study showed that parents reported from 5-29 symptoms with mean 17.59 ( $\mathrm{SD}=6.17)$. Conduct disorder mean was $3.9(\mathrm{SD}=2.10)$, mean hyperactivity was $5(\mathrm{SD}=2.10)$, mean emotional problems was 4.88 ( $\mathrm{SD}=2.47)$, mean peers problems was $3.87(\mathrm{SD}=1.9)$, and mean prosocial problems was $7.17(\mathrm{SD}=1.96)$ (Table 5).
Table 5: Means and Standard Deviations of SDQ and subscales.

\begin{tabular}{|c|c|c|}
\hline Parents-report & Mean & SD \\
\hline SDQ & 17.59 & 6.17 \\
\hline Emotional problems & 4.88 & 2.47 \\
\hline Conduct problems & 3.90 & 2.10 \\
\hline Hyperactivity & 5.00 & 2.10 \\
\hline Peer problems & 3.87 & 1.90 \\
\hline Prosocial behavior & 7.17 & 1.96 \\
\hline
\end{tabular}

Prevalence of General Mental Health Problems Using SDQ by Parents: Using SDQ for parents, $53.7 \%$ of children were rated as being caseness (were considered as having a problem) (cut- 
off point $=17-40), 60.3 \%$ had emotional problems (5-10), 60.3\% had conduct problems (4-10), $22.2 \%$ of them were hyperactive (7-10), 49.3\% had peer problems (4-10), and $21 \%$ had prosocial behaviour (0-4) (Table 6).

Table 6: Prevalence of general mental health problems using SDQ by parents.

\begin{tabular}{|c|c|c|c|}
\hline Parents-report & Normal & Borderline & Abnormal \\
\hline SDQ caseness parents & 25 & 15.8 & 53.9 \\
\hline Emotional problems & 28.8 & 11 & 60.3 \\
\hline Conduct problems & 26 & 13.7 & 60.3 \\
\hline Hyperactivity & 55.6 & 22.2 & 22.2 \\
\hline Peer problems & 23.9 & 26.8 & 49.3 \\
\hline Prosocial behaviour & 52.6 & 21.1 & 21.1 \\
\hline
\end{tabular}

Differences in SDQ and Sociodemographic Variables: In order to find differences in SDQ means according to sociodemographic variables, independentt test for two groups and One Way ANOVA for more than three groups. Tukey's test showed no sex and age differences in total SDQ and subscales. There were statistically significant differences in prosocial behaviour toward children with 5-7 siblings ( $\mathrm{F}(2 / 67)=6.45, \mathrm{p}=0.003$ ) and peer relationship in children with 4 and less siblings $(F(2 / 68)=4.39$, $\mathrm{p}=0.02$ )

Relationships between PTSD, and Behavioural and Emotional Problems Using SDQ: In order to find the relationship between PTSD due to ground incursion of the camp and SDQ, Pearson correlation coefficient test was performed. Result showed that there was significant correlation between total PTSD and total SDQ ( $\mathrm{r}=0.37, \mathrm{p}=[0.001)$, hyperactivity $(\mathrm{r}=0.31, \mathrm{p}=$ $0.001)$, emotional problems $(r=0.50, p=0.001)$, and prosocial behaviour [ $(\mathrm{r}=0.27, \mathrm{p}=0.001$ ) (Table 7).

Table 7: Pearson correlation coefficient test between PTSD, and behavioural and emotional problems using SDQ.

\begin{tabular}{|c|c|c|c|c|c|c|c|c|c|}
\hline & 1 & 2 & 3 & 4 & 5 & 6 & 7 & 8 & 9 \\
\hline \multicolumn{10}{|l|}{ 1.Total PTSD } \\
\hline 2. Intrusion & $.84^{* *}$ & & & & & & & & \\
\hline 3. Avoidance & $.88^{* *}$ & $.64^{* *}$ & & & & & & & \\
\hline 4. Hyperarousal & $.80^{* *}$ & $.54^{* *}$ & $.51^{* *}$ & & & & & & \\
\hline 5.SDQ total & $.37^{* *}$ & $.29^{*}$ & $.38^{* *}$ & $.29^{*}$ & & & & & \\
\hline 6. Conduct problems & .15 & .08 & .13 & .20 & $.82^{* *}$ & & & & \\
\hline 7. Hyperactivity & $.31^{* *}$ & $.28^{*}$ & $.31^{* *}$ & .19 & $.63^{* *}$ & $.32 * *$ & & & \\
\hline 8. Emotional problems & $.50^{* *}$ & $.43^{* *}$ & $.45^{* *}$ & $.37^{* *}$ & $.80^{* *}$ & $.49 * *$ & $.39^{* *}$ & & \\
\hline 9. Prosocial behaviour & $.27^{*}$ & .23 & $.26^{*}$ & .19 & $-.22-$ & $-.31-*$ & $-.12-$ & .07 & 1.00 \\
\hline 10. Peer relationship & $-.06-$ & .03 & $-.02-$ & $-.11-$ & $.57^{* *}$ & $.43^{* *}$ & .02 & $.30^{*}$ & $-.26^{*}$ \\
\hline
\end{tabular}

\section{Discussion}

Our study showed that the most common reported posttraumatic stress reactions were: try to remove it from his memory (46.1\%), have sleep problems (43.4\%), alert and watchful even when there is no obvious need to be (40\%).Children's post traumatic stress reactions scores ranged between 7 and 63. Mean IES-13 items was 39.05. Intrusion subscale mean was 12.05 , avoidance subscale mean was 15.09 , and hyperarousal subscale mean was 11.86. According to cut off point of 33 and more as PTSD, $67.1 \%$ had post-traumatic stress reactions. Such findings were consistent with study of children and parents exposed to shieling of Gaza in 2006 in which each child experienced 8 traumatic events, and 138 children out of 197 (70.1\%) were likely to present with PTSD Thabet et al. [12]. Bronstein and Montgomery [13] reviewed studies that assessed psychological distress in refugee children living in Western countries in 2003-2008. In total, 3,003 children from 40 countries were evaluated. This study showed that post-traumatic stress-disorder rates were 19\%-54\%, while depression was 3\%-30\% in refugee children; other emotional and behavioural problems also existed within the sample. Our high rate of PTSD was found in study of children in the middle areas of the Gaza Strip in which the prevalence of PTSD in children was $70.1 \%$ Thabet et al. [6]. Our study high rate of PTSD was not consistent with study of survivors of sexual violence during war $(\mathrm{N}=181)$ who were participants in the longitudinal War-Affected Youth Survey (WAYS) study in Northern Uganda. Sixty-six ( $\mathrm{n}=119$, $66 \%)$ reported sexual abuse: $35 \%(n=63)$ of whom returned from captivity with at least 1 child, and $43 \%(n=78)$ met the criteria for PTSD (Impact of Events Scale-Revised score [IES-R] <33). Our study findings were inconsistent with study of Amone P'Olak et al. [14] study explored whether feelings of anger, shame, and guilt mediated the effects of war experiences and PTSD and if this association is heightened in former child soldiers from Northern Uganda. Nearly $40 \%$ of the sample were former child soldiers (N = 122), and 189 were civilians. A total of 35.5\% met the proposed ICD-11 criteria for PTSD (Murphy et al., 2018). Our explanation of high rate of PTSD in this time is the severity of the traumatic events in which all the camp inhabitants exposed to bombardment, shelling of the area, and shooting with more than 150 people was killed at that incursion in Feb. 2008. The study showed that the most commonly reported behavioural and emotional problems in 
children by parents were: considerate of other people's feelings (59.5\%), shares readily with other children (54.1\%), and restless, overactive, cannot stay still for long (49.3\%). The study showed that parents reported from 5-29 symptoms with mean 17.59, conduct disorder mean was 3.9 , mean hyperactivity was 5 , mean emotional problems was 4.88 , mean peers problems was 3.87 , and mean prosocial problems was 7.17.

Such findings were inconsistent with other studies which found lower mean of mental health problems, Lehmann et al. [15] in study of 396 foster children between the age of 6 and 12 years who had lived for at least 5 months in foster families in the 63 municipalities encompassed by the Regional Office for Children, Youth and Family Affairs -South (Bufetat) in Norway. Mean Total Difficulties score was $15.21 ; 3.46$ on emotional subscale; 2.94 on conduct subscale; 6.05 on hyperactivity subscale; 2.76 on peer problem subscale; 6.82 on prosocial subscale; and 2.67 on the Impact scale. Using SDQ for parents, $53.7 \%$ of children were rated as being caseness, $60.3 \%$ had emotional problem, $60.3 \%$ had conduct problems, $22.2 \%$ of them were hyperactive, $49.3 \%$ had peer problems, and $21 \%$ had prosocial behavior. Such rate of mental health problems was inconsistent with some of the previous studies conducted in the Gaza Strip. Thabet et al. [16] in study 420 children aged 9-18 years were selected from two cities, two camps and three villages in the Gaza Strip. The results showed that $49.6 \%$ of children were rated caseness according to their parents. Thabet et al. [17] in study a sample of 114 Palestinian children. The results estimated of that $18.4 \%$ of children were cases according to parent, $21.1 \%$ had conduct problems, $6.1 \%$ had emotional problems, $6.1 \%$ had hyperactivity/inattention, $77.6 \%$ had peer relationship problems, and $1.8 \%$ had prosocial behaviour. While, $44.1 \%$ of children were rated as caseness, $10.8 \%$ had emotional problems, $29 \%$ had conduct problems, $24.7 \%$ had hyperactivity/inattention, $64.5 \%$ had peer relationship problems, and $9.7 \%$ had prosocial behaviour according to teachers. Thabet and Thabet [18] in another study aimed to investigate the relationship between trauma, mental health, and coping strategies among children living in south of Gaza Strip. Results showed that prevalence of general mental health problems using SDQ using self-reported, parents and teachers forms $(19.4 \%$, 24.3\%, and 28.4\%). Thabet and Vostanis [19] in study of 200 parents and 200 children age 9-18 in the middle area of the Gaza Strip. The results estimated that $42.7 \%$ of children being rated as caseness by parents, $36.8 \%$ had conduct disorder, $22.8 \%$ had hyperactivity, $24.4 \%$ had emotional problems, $60.1 \%$ had peer's problems, and $20.2 \%$ had prosocial problems. Result showed that there was significant correlation between total PTSD and total SDQ hyperactivity, emotional problems, and prosocial behaviour. Our results consistent with study of Thabet et al. which looked at the behavioural and emotional problems of 309 Palestinian preschoolers and found that direct and indirect exposure to war trauma increases the risk of poor mental health Thabet et al. [20]. Similarly, such findings were consistent with results of study of
Massad et al. [21] examining exposures to traumatic events and mental health among 455 refugee Palestinian children between the ages of 5-16 years old, and randomly selected from 18 Bedouin communities throughout the West Bank, including East Jerusalem. Based on reports by mothers, teachers and children, $44 \%$ of the participants in the study had a probable psychiatric disorder. Exposure to traumatic events, fair/poor maternal selfrated mental health, and younger age were positively associated with child mental health problems. Similarly, in a study conducted between January 2016 and June 2016. Clinical interviews were conducted with 89 children and their families, and were performed by native speakers of Arabic and Persian who had been primarily educated in these languages and were living in Turkey. A strength and difficulties questionnaire (SDQ) that had Arabic and Persian validity and reliability was applied to both children and their families. Among these children, 47 (52.8\%) had come from Syria, 27 (30.3\%) from Iraq, 14 (15.7\%) from Afghanistan, and 1 (1.1\%) from Iran. A psychiatric disorder was found in 44 (49.4\%) of the children Sapmaz et al. [22].

\section{Clinical Implications}

Our findings have public health and clinical implications because they highlight the importance of child mental health including PTSD as a significant factor affecting children's psychosocial development. There is a need for immediate psychosocial interventions targeting children mental health, to help children with mental health problems. We need to educate and support parents, teachers and other caregivers so they can support the emotional well-being of children exposed to political violence. Such interventions may consist of group discussion meetings for mothers to support them and increase their sense of well-being, self-confidence and ability to care for their children in this difficult situation [23].

\section{References}

1. Elbedour S, Onwuegbuzie AJ, Ghannam J, Whitcome JA, Abu Hein F (2007) Post-traumatic stress disorder, depression, and anxiety among Gaza Strip adolescents in the wake of the second Uprising (Intifada). Child Abuse \& Neglect: The International Journal 31(7): 719-729.

2. Qouta S, Punamäki RL, El Sarraj E (2003) Prevalence and determinants of PTSD among Palestinian children exposed to military violence. European Child \& Adolescent Psychiatry 12(6): 265-272.

3. Thabet AA, Tawahina AA, El Sarraj E, Vostanis P (2008) Exposure to war trauma and PTSD among parents and children in the Gaza strip. European Child \& Adolescent Psychiatry 17(4): 191-199.

4. El-khodary B, Samara M (2018) The effect of exposure to wartraumatic events, stressful life events, and other variables on mental health of Palestinian children and adolescents in the 2012 Gaza War The Lancet 391(1): S6.

5. Dawas M, Thabet AA (2017) The relationship between traumatic experience, posttraumatic stress disorder, resilience, and posttraumatic growth among adolescents in Gaza Strip. JOJ Nurse Health Care 5(1).

6. Thabet AM, Vostanis P (2017) Effect of Trauma on Mental Health of Parents and Children in the Middle Area of the Gaza Strip. JOJ Nurse Health Care 3(5). 
7. Al-Sheikh N, Thabet AA (2017) Post-Traumatic Stress Disorder due to War Trauma, Social and Family Support among Adolescent in the Gaza Strip. Journal of Nursing and Health Sciences 3(2): 1-12.

8. Lee SH, Kim EJ, Noh J, Chae J (2018) Factors Associated with Posttraumatic Stress Symptoms in Students Who Survived 20 Months after the Sewol Ferry Disaster in Korea. J Korean Med Sci 33(11): e90.

9. Smith P, Perrin S, Dyregrov A, Yule W (2003) Principal components analysis of the impact of event scale with children in war. Personality and Individual Differences 34(2): 315-322.

10. Goodman R (1997) The strengths and difficulties questionnaire: a research note. J Child Psychol Psychiatry 38(5): 581-586.

11. Thabet AA, Vostanis P (1998) Social adversities and anxiety disorders in the Gaza Strip. Archives of Childhood Diseases 78(5): 439-442.

12. Thabet AA, Tawahina AA, El Sarraj E, Vostanis P (2008) Exposure to war trauma and PTSD among parents and children in the Gaza strip. European Child \& Adolescent Psychiatry 17: 191-199.

13. Bronstein I, Montgomery P (2011) Psychological distress in refugee children: a systematic review. Clin Child Fam Psychol Rev 14(1): 44-56.

14. Amone-POlak K, Elklit A, Dokkedahl SB (2017) PTSD, Mental Illness, and Care Among Survivors of Sexual Violence in Northern Uganda: Findings From the WAYS Study. Psychological Trauma 10(3): 282-289.

15. Lehmann S, Bøe T, Breivik K (2017) The internal structure of fosterparent completed SDQ for school-aged children. PLoS ONE 12(6): e0176625.

This work is licensed under Creative

Commons Attribution 4.0 License

DOI: 10.19080/JOJNHC 2018.08.555734
16. Thabet AA, Abu Tawahina A, El Sarraj E, Vostanis P (2007) Children Exposed to Political Conflict: Implications for Health Policy. Harvard Health Policy Review 8(2): 47-57.

17. Thabet AA, Abu Tawahina A, El Sarraj E, Vostanis P (2009) Impact of Trauma on PTSD and Anxiety among Palestinian School-age Children. Arab psynet E Journal 21(22): 244-249.

18. Thabet AA, Thabet SS (2017) Coping with trauma among children in South of Gaza Strip. Psychol Cogn Sci Open J 3(2): 36-47.

19. Thabet AM, Vostanis P (2017a) Effect of Trauma on Mental Health of Parents and Children in the Middle Area of the Gaza Strip. JOJ Nurse Health Care 3(5).

20. Thabet AA, Karim, K, Vostanis P (2006) Trauma Exposure in Pre-school Children in a War Zone. British Journal of Psychiatry 188: 154-158.

21. Massad S, Khammash O, Shute R (2017) Political violence and mental health of Bedouin children in the West Bank, Palestine: a crosssectional study. Medicine, conflict and Survival 33(3): 188-206.

22. Sapmaz SY, Tanrıverdi PU, Öztürk M, Gözaçanlar Ö, Ülker GU, et al. (2017) Immigration-related mental health disorders in refugees 5-18 years old living in Turkey. Neuropsychiatric Disease and Treatment 13: 2813-2821.

23. Altawil M, Nel PW, Asker A, Samara M, Harrold D (2008) The effects of chronic war trauma among Palestinian children. In: M. Parsons (Eds.), Children: The invisible victims of war-An interdisciplinary study. DSM Technical Publications Ltd, Peterborough, UK.

\section{Your next submission with Juniper Publishers will reach you the below assets}

- Quality Editorial service

- Swift Peer Review

- Reprints availability

- E-prints Service

- Manuscript Podcast for convenient understanding

- Global attainment for your research

- Manuscript accessibility in different formats

( Pdf, E-pub, Full Text, Audio)

- Unceasing customer service

Track the below URL for one-step submission https://juniperpublishers.com/online-submission.php 